\title{
Rapid Phosphine Exchange on 1.5-nm Gold Nanoparticles
}

Janet Petroski, Mei H. Chou, and Carol Creutz

Chemistry Department, Brookhaven National Laboratory, Upton, New York 11973-5000.

\section{Experimental Section}

\section{Supplementary Material}

The " $\mathrm{Au}_{101}\left(\mathrm{PPh}_{3}\right)_{21} \mathrm{Cl}_{5}$ " nanoparticles were prepared as described by Hutchison. ${ }^{1}$ Commercial reagents and solvents were generally used without further purification: $\mathrm{HAuCl}_{4}$ (Aldrich), triphenylphosphine (Eastman), sodium borohydride (Aldrich), sodium nitrite (Fisher). The tedious washing procedure ${ }^{1}$ was facilitated somewhat by centrifuging (20,000 rpm; Beckman Coulter Allegra 64R centrifuge) the suspended solution contained in matched $30 \mathrm{~mL}$, teflon sample tubes after each washing to isolate the nanoparticles for their next washing. The product nanoparticles were characterized by transmission electron microscopy (JEOL 100CXII) (Figure S1) and by ${ }^{1} \mathrm{H}$ NMR and UV-vis spectroscopy. NMR spectra were recorded on a Bruker Avance $400 \mathrm{MHz}$ spectrometer. UV-vis. spectra were obtained with a Hewlett-Packard 8452A diode array spectrometer. As shown in Figure S2, the UV-vis spectrum of " $\mathrm{Au}_{101}\left(\mathrm{PPh}_{3}\right)_{21} \mathrm{Cl}_{5}$ " solutions in $\mathrm{CH}_{2} \mathrm{Cl}_{2}$ exhibits a peak/inflection at $420 \mathrm{~nm}$ with an absorbance of $0.5\left(\varepsilon\right.$ per Au $3.3 \times 10^{3} \mathrm{M}^{-1}$ $\left.\mathrm{cm}^{-1}\right)$ and no peak at $500-550 \mathrm{~nm}\left(\varepsilon\right.$ per Au $\left.\leq 2.8 \times 10^{3} \mathrm{M}^{-1} \mathrm{~cm}^{-1}\right)$ which would arise from the plasmon absorption of $\geq 2.5$-nm particles.

The ${ }^{1} \mathrm{H}$ NMR spectrum was as previously reported, ${ }^{1}$ with a broad peak at ca. $\delta 7.3$ due to bound $\mathrm{PPh}_{3}$ (Figure S3) and a narrower peak at $\delta 7.66$ in $\mathrm{CD}_{2} \mathrm{Cl}_{2}$; free $\mathrm{PPh}_{3}$ exhibits a complex multiplet at $\delta 7.21-7.27$ and a ${ }^{31} \mathrm{P}\left\{{ }^{1} \mathrm{H}\right\}$ resonance at $\delta-4.3$. At room temperature we could not observe a ${ }^{31} \mathrm{P}$ resonance for the metal cluster solution. (At $-60{ }^{\circ} \mathrm{C}$, the bound $\mathrm{PPh}_{3}$ was observed at $\delta 42.7$ for a solution of " $\mathrm{Au}_{101}\left(\mathrm{PPh}_{3}\right)_{21} \mathrm{Cl}_{5}$ " containing no added $\mathrm{PPh}_{3}$ (Figure S4).)

Accordingly we studied the behavior of the free $\mathrm{PPh}_{3}$ resonance in the presence of small amounts of added gold cluster. Aliquots (10 to $150 \mu \mathrm{L}$ ) of " $\mathrm{Au}_{101}\left(\mathrm{PPh}_{3}\right)_{21} \mathrm{Cl}_{5}$ " dissolved in $\mathrm{CD}_{2} \mathrm{Cl}_{2}$ (3.3 $\mathrm{mg}$ in $0.25 \mathrm{~mL}$ ) were added to $0.6 \mathrm{~mL}$ of $0.1 \mathrm{MPPh}_{3}$ in $\mathrm{CD}_{2} \mathrm{Cl}_{2}$, and the ${ }^{31} \mathrm{P}$ NMR spectrum at 25 ${ }^{\circ} \mathrm{C}$ was determined after each addition. The $31 \mathrm{P}$ peak was found to shift from $\delta-4.3$ to higher field and to broaden as the cluster concentration increased (Figure S5). The 31P peak shown in 
Fig. S5 is artificially broadened and the tabulated ${ }^{2} T_{2}$ value was used in treating the line broadening data.

Figure S1. Transmission electron micrograph of the particles.

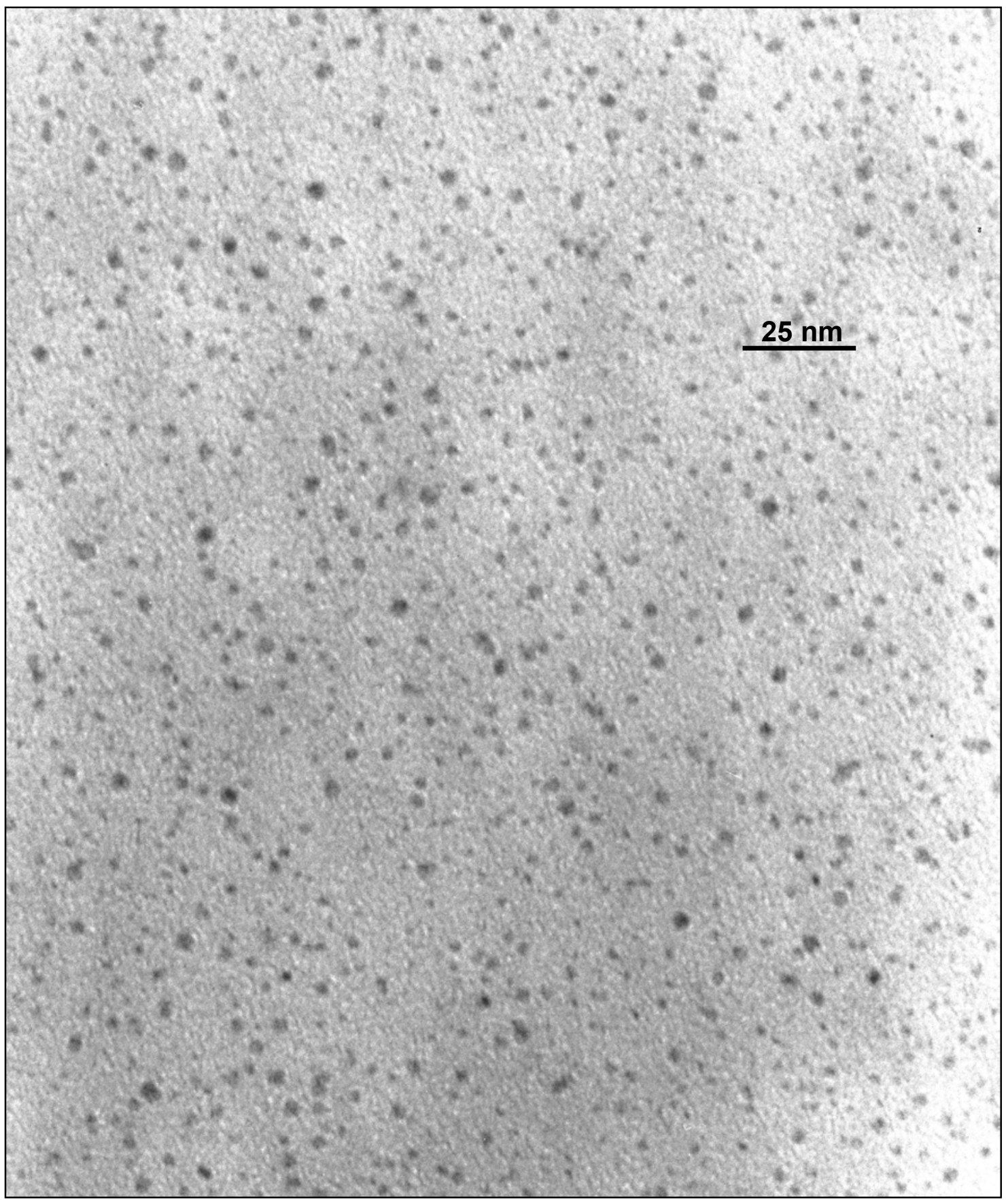




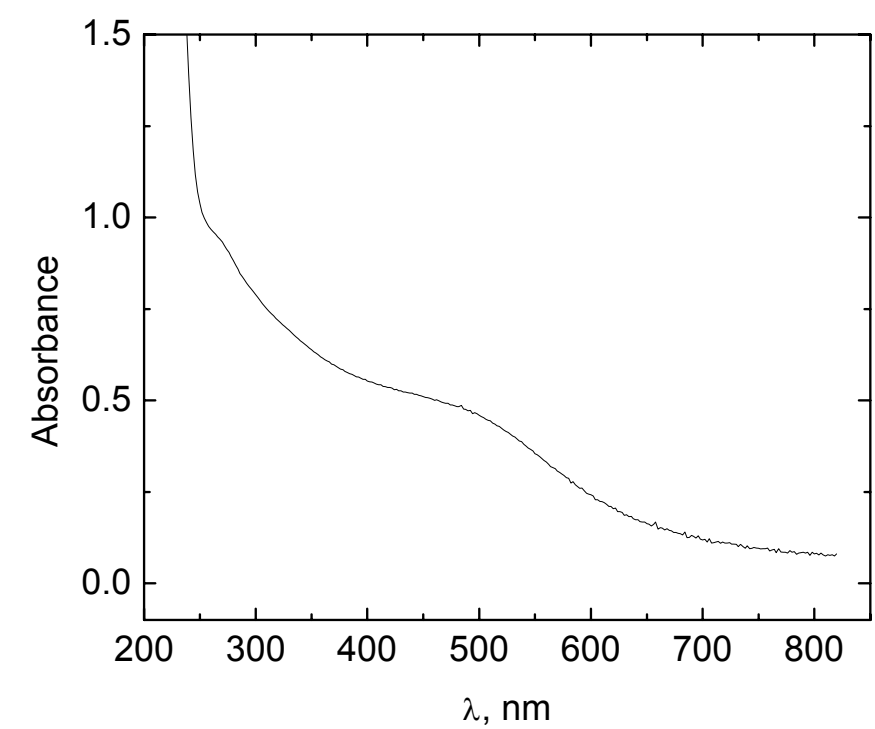

Figure S2. Spectrum of $1.91 \mathrm{mg}$

" $\mathrm{Au}_{101}\left(\mathrm{PPh}_{3}\right)_{21} \mathrm{Cl}_{5}$ " in $50 \mathrm{~mL} \mathrm{CH} \mathrm{Cl}_{2}$.

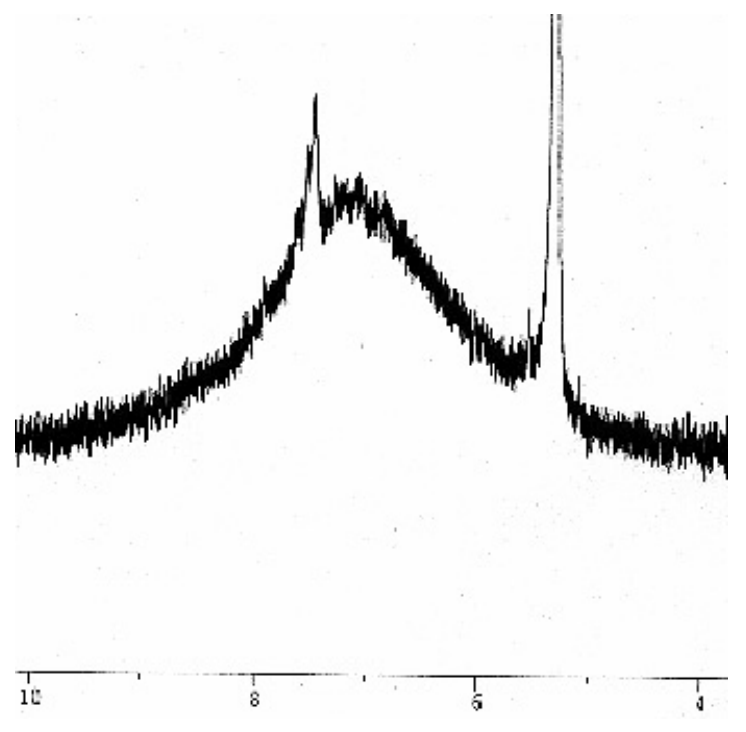

Figure S3. ${ }^{1} \mathrm{H}$ NMR for a solution of " $\mathrm{Au}_{101}\left(\mathrm{PPh}_{3}\right)_{21} \mathrm{Cl}_{5}$ " (6.5 mg dissolved in $0.6 \mathrm{~mL} \mathrm{CD} \mathrm{Cl}_{2}$ ) at $-60{ }^{\circ} \mathrm{C}$.

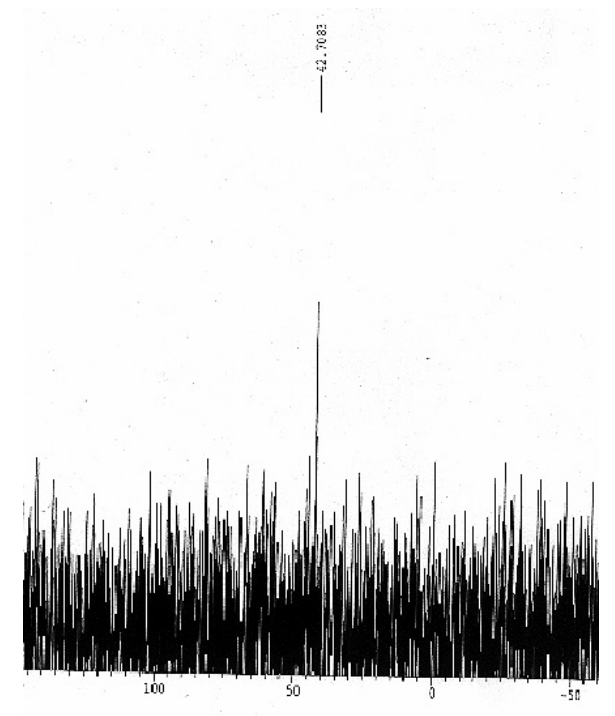

Figure S4. At $-60{ }^{\circ} \mathrm{C}$, the bound $\mathrm{PPh}_{3}$ was observed at $\delta 42.7$ for a solution of " $\mathrm{Au}_{101}\left(\mathrm{PPh}_{3}\right)_{21} \mathrm{Cl}_{5}$ " (6.5 mg dissolved in $0.6 \mathrm{~mL} \mathrm{CD}_{2} \mathrm{Cl}_{2}$ ) containing no added $\mathrm{PPh}_{3}$. 

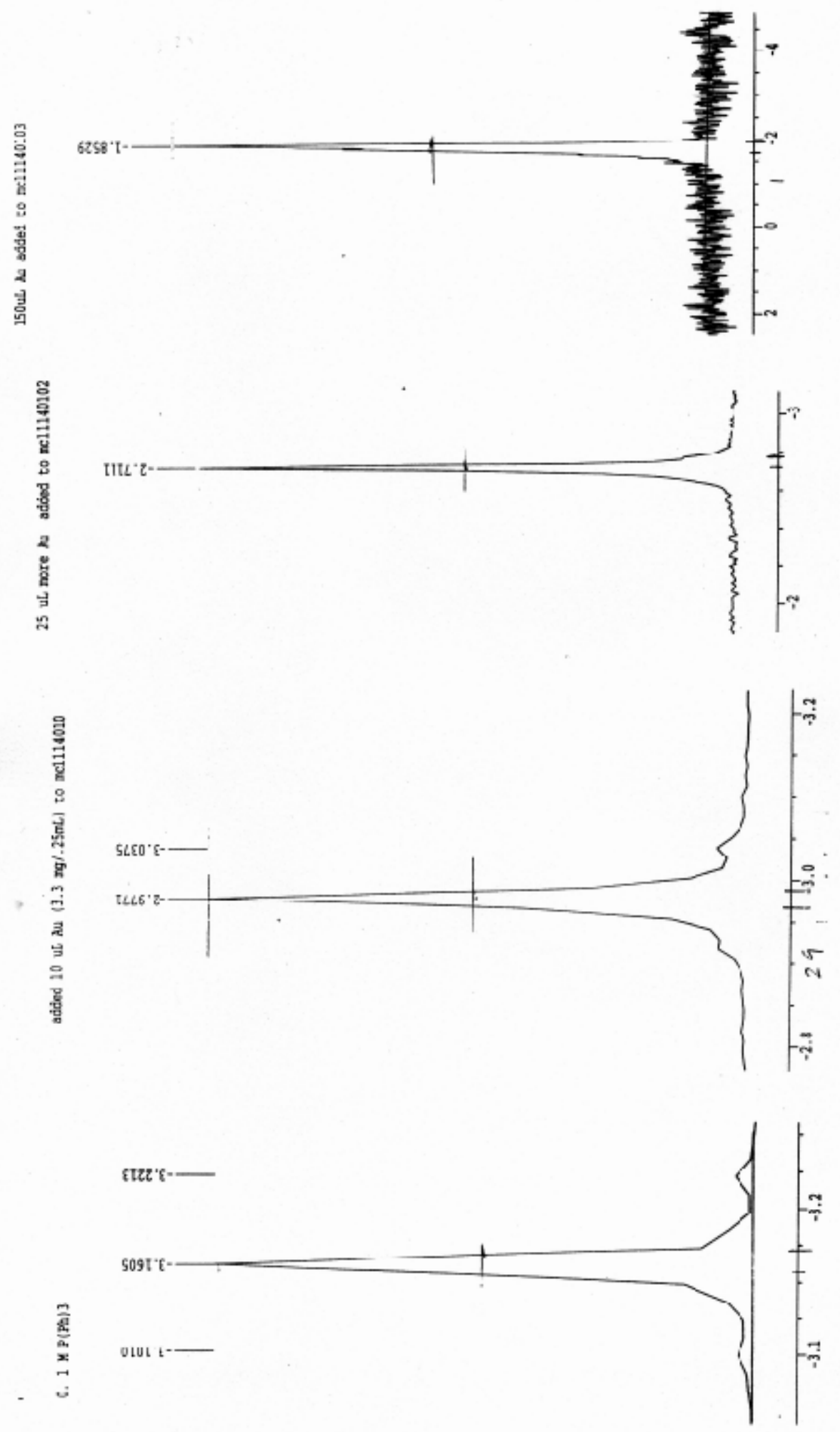

Figure S5. The triphenylphosphine resonance ${ }^{31} \mathrm{P}$ resonance with increasing nanoparticle concentration. 
(1) Weare, W. W.; Reed, S. M.; Warner, M. G.; Hutchison, J. E. J. Am. Chem. Soc. 2000, 122, 12890-12891.

(2) Verkade, J. G.; Quin, L. D., Eds. Phosphorus-31 NMR Spectroscopy in Stereochemical Analysis: Organic Compounds and Metal Complexes; VCH: Deerfield Beach, Florida, 1987; Vol. 8. 